\title{
A PROTEÇÃO DOS DIREITOS DOS REFUGIADOS AMBIENTAIS NO ORDENAMENTO JURÍDICO BRASILEIRO
}

\section{THE PROTECTION OF THE RIGHTS OF ENVIRONMENTAL REFUGEES IN BRAZILIAN LEGAL ORDINANCE}

\author{
Francisco Mendes Chaves Neto ${ }^{1}$ \\ Gustavo Paschoal Teixeira de Castro Oliveira ${ }^{2}$
}

\section{RESUMO}

O presente artigo busca promover uma análise acerca dos direitos dos refugiados ambientais no ordenamento jurídico brasileiro, apresentando conceitos, aspectos históricos e possíveis soluções para o reconhecimento do status de refugiado ambiental, tanto em âmbito internacional quanto pelo ordenamento jurídico brasileiro. Ademais, será analisado como se dá o processo de acolhimento e efetivação dos direitos deste grupo social no Brasil, bem como a necessidade de regulamentação sobre essa temática. A metodologia empregada na pesquisa foi o método de abordagem dedutivo, através do estudo doutrinário e análise da legislação e jurisprudência. Por fim, vislumbra-se que os resultados apresentados por este artigo permitirão a elaboração de referenciais na área dos Direitos Humanos e do Direito Internacional Ambiental, possibilitando um suporte para 0 entendimento da problemática que envolve a questão dos refugiados ambientais.

Palavras-chave: Direitos humanos. Migrações. Meio ambiente. Mudanças climáticas. Refugiados ambientais.

\section{ABSTRACT}

This article seeks to promote an analysis of the rights of environmental refugees in the Brazilian legal system, presenting concepts, historical aspects and possible solutions for

\footnotetext{
${ }^{1}$ Bacharel em Direito pela Universidade Federal do Tocantins. Advogado. E-mail: mendeschaves2@gmail.com ORCID https://orcid.org/0000-0002-2184-4996

${ }^{2}$ Doutor em Direito das Relações Internacionais pelo Centro Universitário de Brasília. Professor adjunto na Universidade Federal do Tocantins e no Centro Universitário Luterano de Palmas. Advogado. E-mail: paschoal@mail.uft.edu.br ORCID https://orcid.org/0000-0002-3045-2097
} 
the recognition of the status of environmental refugee, both in the international scope and in the Brazilian legal system. In addition, it will be analyzed how the process of reception and fulfillment of the rights of this social group in Brazil, as well as the need for regulation on this subject, is analyzed. The methodology used in the research was the method of deductive approach, through doctrinal study and analysis of legislation and jurisprudence. Finally, it is clear that the results presented by this article will allow the elaboration of references in this area of International Human Rights Law and International Environmental Law, providing a support for the understanding of the problematic that involves the issue of environmental refugees.

Keywords: Human rights. Migrations. Environment. Climate changes. Environmental refugees.

\section{INTRODUÇÃO}

As mudanças climáticas verificadas nos últimos anos, em que pese sua causa natural e inerente à evolução geológica da Terra, têm sido intensificadas em grande parte por consequência da ação antrópica, cujo cerne está na exploração excessiva dos recursos naturais sem a devida preocupação com a sustentabilidade e preservação do meio ambiente.

Entre os efeitos das mudanças climáticas, tem-se observado o aumento da ocorrência de grandes catástrofes naturais que têm provocado o deslocamento forçado de milhões de pessoas em diferentes partes do globo, gerando assim uma grande preocupação para toda a comunidade internacional.

Nesse contexto de grandes deslocamentos humanos forçados e o aumento do número de pessoas em situação de refúgio, ocasionados também por consequência de conflitos armados, perseguições religiosas, políticas e por questões étnicas, observa-se que, ante à problemática das mudanças climáticas e sobretudo dos efeitos dos desastres naturais, vem surgindo no cenário internacional um amplo debate acerca de uma nova categoria de refugiado, os chamados "refugiados ambientais".

Observa-se que a nova categoria de refugiados ambientais ainda não foi classificada em acordos ou tratados internacionais. Sendo assim, é preciso criar mecanismos para que essas pessoas sejam reconhecidas e passem a receber proteção adequada. Nesse sentido, é necessário que se crie também uma definição legal para o 
conceito de refugiado ambiental, de maneira que esse grupo social possa receber uma assistência similar a dos demais tipos de refugiados.

Nesse cenário, vislumbra-se que as mudanças climáticas globais associadas à crise migratória internacional podem se tornar uma preocupação de segurança mundial devido ao aumento dos conflitos internacionais, tendo como efeito direto a violação dos direitos humanos já consagrados em normas de direito interno e tratados internacionais.

Tendo em vista que a realidade dos refugiados está cada vez mais próxima de nós, faz-se necessário refletir sobre o seguinte questionamento: quais são os mecanismos de proteção dos direitos dos refugiados ambientais existentes no ordenamento jurídico brasileiro?

Diante disso, a presente investigação buscará responder a esta questão, bem como proporcionar o conhecimento das estruturas que envolvem a tutela dos direitos desta categoria específica de refugiado, especialmente dentro do ordenamento jurídico pátrio, associando-o às mudanças climáticas e ao aumento do fluxo internacional de imigrantes no contexto da atual crise humanitária dos refugiados.

A metodologia a ser utilizada compreende os procedimentos técnicos de levantamento bibliográfico e estudo de processos judiciais e legislações correlatas, sobretudo a análise de tratados e convenções internacionais, normas internas e doutrinas acerca da temática dos refugiados ambientais.

\section{O DIREITO INTERNACIONAL DOS REFUGIADOS}

O Direito Internacional dos Refugiados é um dos pilares do Direito Internacional dos Direitos Humanos, tendo como finalidade principal proteger os indivíduos que foram forçados a abandonar seus lares e a viver em outros países, principalmente em função da raça, da opinião política, da religião ou por pertencerem a um determinado grupo social.

Nesse sentido, este ramo do Direito Internacional constitui-se em um conjunto de instrumentos normativos com o objetivo de tutelar a problemática dos deslocamentos humanos forçados em decorrência de condições pré-determinadas e específicas em 
âmbito mundial, situação que tem gerado amplos debates em toda a comunidade internacional.

Em sendo um tema essencialmente multidisciplinar, o estudo da questão dos refugiados demanda a necessidade de estudo nas áreas do Direito Internacional Público e do Direito Internacional dos Direitos Humanos, bem como a análise dos demais aspectos que envolvem a ordem internacional (aspectos políticos, econômicos, sociais e humanitários).

Segundo Jubilut (2007), uma parte da doutrina aponta o Direito Internacional dos Refugiados como pertencente ao Direito Humanitário, que vem a ser as regras reguladoras da guerra, pois quando ocorrem conflitos bélicos a problemática dos refugiados é aprofundada (JUBILUT, 2007, p. 31).

No entanto, os refugiados podem também solicitar refúgio com base em outros tipos de perseguições, ou ainda em função de violações de direitos humanos. Ou seja, a guerra é somente uma das causas motivadoras do refúgio, não sendo a única.

Por isso, vislumbra-se que seja mais adequado incluir o Direito Internacional dos Refugiados como uma vertente do Direito Internacional dos Direitos Humanos, que engloba os Direitos Humanos propriamente ditos, o Direito Humanitário e o Direito Internacional dos Refugiados.

Tal concepção é a defendida pelo Alto Comissariado das Nações Unidas para os Refugiados (ACNUR) em seu documento "Compilación de instrumentos jurídicos internacionales: principios y criterios relativos a refugiados y Derechos Humanos (ACNUR,1992, p. X)".

Dessa forma, verifica-se que o estudo do Direito Internacional dos Refugiados somente pode ser efetuado adequadamente de modo multidisciplinar, a exemplo do estudo do Direito Internacional dos Direitos Humanos, uma vez que várias áreas do conhecimento são necessárias para a sua compreensão.

Por todo o exposto, vislumbra-se que o Direito Internacional dos Refugiados é uma vertente do Direito Internacional dos Direitos Humanos, sendo esta a sua natureza jurídica.

Essa natureza jurídica implica, segundo Liliana Jubilut (2007), em: 
Aspectos positivos e aspectos negativos; o principal aspecto positivo é o fato de ser ele parte de um elenco de direitos universais, indivisíveis, interdependentes, inter-relacionados e essenciais ao ser humano, e o principal aspecto negativo é a questão da sua efetivação. (JUBILUT, 2007, p. 64).

Sendo assim, por ser um instituto de proteção do ser humano, a compreensão da inserção do direito dos refugiados como vertente do Direito Internacional dos Direitos Humanos é essencial para compreender esta temática, bem como o seu processo de efetivação.

\subsection{DEFINIÇÕES DE ASILO E REFÚGIO}

Vislumbra-se que parte da doutrina, como por exemplo Guido Soares (2002), entende que o asilo e o refúgio são institutos jurídicos distintos e não se deve falar em formas de proteções abrangidas pelo direito de asilo lato sensu. Todavia, segundo Liliana Jubilut (2007), essa postura não merece prosperar, pois ambos os institutos visam a proteção do ser humano em face de perseguição, geralmente realizada pelo Estado, sendo, portanto, similares em sua essência e, dessa maneira, institutos assemelhados.

Ademais, os institutos apresentam um caráter de complementaridade, tanto em relação aos sistemas nacionais de proteção quanto entre si, tendo em vista que o instituto do asilo é mais abrangente, podendo ser usado quando não há a possibilidade de aplicação do instituto mais específico do refúgio.

Tendo em vista que o objeto do presente estudo é a tutela do Direito dos Refugiados pelo ordenamento jurídico brasileiro, constatou-se que para a legislação pátria há diferenças entre os dois institutos. Diante disso, faz-se necessário analisar a distinção entre asilo e refúgio.

\subsection{Instituto do Asilo}

Vislumbra-se que o instituto do asilo tem a sua origem na Antiguidade clássica, mais precisamente na civilização grega, em que era frequentemente utilizado. Consiste, 
em linhas gerais, no instituto pelo qual um Estado fornece imunidade a um indivíduo em face de perseguição sofrida por esse em outro Estado.

Contudo, é a partir da Revolução Francesa que o asilo passa a sofrer uma alteração: até então os beneficiados pelo asilo eram, em sua grande maioria, criminosos comuns, sendo que os chamados "criminosos políticos" não eram contemplados por esse instituto. Com as alterações políticas da Revolução Francesa, o asilo passou a ser concedido aos "criminosos políticos" e não mais a criminosos comuns, em virtude dos ideais de liberdade.

Por esse instituto jurídico um Estado tem o poder discricionário de conceder proteção a qualquer pessoa que se encontre sob sua jurisdição. É o que modernamente denomina-se asilo político, uma vez que é concedido a indivíduos perseguidos por razões políticas.

Vislumbra-se que, segundo Jubilut (2007), o asilo político se subdivide em dois tipos: asilo territorial - verificado quando o solicitante se encontra fisicamente no âmbito territorial do Estado ao qual solicita proteção; e asilo diplomático - o asilo concedido em extensões do território do Estado solicitado como, por exemplo, em embaixadas, ou em navios, ou aviões da bandeira do Estado.

$O$ instituto do asilo em ambas as modalidades é verificado contemporaneamente, sobretudo na prática do Direito Internacional Público da América Latina, muito em função das instabilidades políticas que ocorreram na região.

Especificamente no caso brasileiro tem-se o fundamento do direito de asilo lato sensu no artigo 4ํㅜㄹ inciso II, da Constituição Federal, que trata da prevalência dos direitos humanos nas relações internacionais brasileiras.

Ademais, a regulamentação do asilo político especificamente se encontra no artigo 4º, inciso X, da Constituição Federal e nos artigos 28 e 29 da Lei 6.815/ 1980 (Estatuto do Estrangeiro).

\subsection{Instituto do Refúgio}

Além do asilo político, o direito de asilo possibilitou também a criação de outra modalidade prática de solidariedade internacional: o refúgio. 
Tem-se que o refúgio é um instituto do Direito Internacional muito mais recente e, atualmente, com abrangência maior e tipificada. Isso significa que não se trata de um ato discricionário do Estado concessor, pois o reconhecimento do status de refugiado está vinculado a diplomas e hipóteses legais bem definidas.

Vislumbra-se que, atualmente, o refúgio é um instituto regulado por uma convenção, a chamada Convenção das Nações Unidas relativa ao Estatuto dos Refugiados, também conhecida como Convenção de Genebra de 1951, revisada pelo Protocolo de 1967, o qual assegura a alguns indivíduos em função de determinadas circunstâncias o status de refugiado.

Atualmente, após uma longa construção doutrinária, ficou estabelecido que, de acordo com a Convenção de Genebra de 1951 e com o Protocolo de 1967, o status de "refugiado" será reconhecido a qualquer pessoa que sofra perseguição em seu Estado de origem ou residência habitual, por força de sua raça, nacionalidade, religião, opinião política ou associação a determinado grupo social, enquanto o asilo tem sua prática limitada à perseguição política.

Tais hipóteses para o reconhecimento do status de refugiado são as elencadas nos diplomas internacionais universais que tratam da matéria e constituem os padrões mínimos de proteção a serem resguardados. Contudo, a efetivação dessa proteção ocorre no âmbito interno de cada Estado, os quais têm, consequentemente, a faculdade de aumentar este rol.

Em suma, são elementos essenciais da definição de refúgio a perseguição, o fundado temor, ou justo temor, e a extraterritorialidade.

O ACNUR estabelece em seu "Manual de Procedimentos e Critérios a Aplicar para Determinar a Condição de Refugiado", que perseguição é qualquer ameaça à vida ou à liberdade, devendo ser auferida tanto por critérios objetivos como por critérios subjetivos.

Para James Hathaway (2007), os documentos que compõem a Carta Internacional de Direitos Humanos contêm direitos que não podem ser violados em qualquer hipótese, direitos, portanto, inderrogáveis, entre os quais se encontram o direito a não ser submetido à tortura, o direito a não ser submetido à escravidão, a 
liberdade de pensamento, de consciência e de religião e a garantia de não sofrer prisão arbitrária; sempre que houver violação a esses direitos existe perseguição.

Por fim, esses documentos consagram direitos cuja efetivação varia de Estado para Estado com base nos recursos disponíveis por eles para a sua implementação, tais como o direito ao trabalho, à alimentação e à saúde. Quando o Estado não garantir esses direitos dentro de seus recursos disponíveis existe perseguição.

O segundo elemento essencial da definição de refúgio vem a ser o fundado temor de que a perseguição ocorra. Esse elemento é mais recente na história do instituto do refúgio, tendo passado a existir apenas após a introdução do sistema individual de verificação da condição de refugiado, dado que, enquanto a verificação era coletiva, o simples fato de pertencer a um grupo entendido como perseguido bastava para que o indivíduo passasse a gozar da condição de refugiado.

Em função da impossibilidade de tratamento equitativo a todos os solicitantes de refúgio, passou-se a utilizar o temor objetivo como meio de verificação da condição de refugiado.

Assim, de acordo com a doutrina majoritária, adotou-se a posição de que o temor subjetivo deve ser presumido e que se deve proceder à verificação das condições objetivas do Estado do qual provém o solicitante em relação a ele para se chegar à conclusão de que esse temor é fundado.

O terceiro elemento essencial da definição de refúgio é o fato de o solicitante se encontrar fora de seu país de origem ou residência, o que se pode denominar extraterritorialidade. Tal elemento é essencial também ao asilo territorial e vem a ser um reflexo do princípio de não intervenção, consagrado pela Ordem Internacional de Vestfália e positivado no artigo $2^{\circ}$ e $7^{\circ}$ da Carta da ONU.

Além de ter os elementos essenciais da definição de refugiado, o solicitante deve ser merecedor da proteção, isto é, não ser abrangido pelas hipóteses de vedação da concessão. Uma vez comprovado o fundado temor de perseguição de um solicitante de refúgio que se encontre fora de seu Estado de origem e/ou residência habitual e que seja merecedor e carecedor, o status de refugiado é reconhecido por meio de uma decisão declaratória. 
Diante de todo o exposto, tem-se que os dois institutos, apesar de terem diferenças que os tornam institutos distintos, apresentam o mesmo objetivo e a mesma base de atuação que é livrar seres humanos de perseguições por meio de sua acolhida em outro Estado no qual poderão gozar de seus direitos mais fundamentais e manter sua dignidade.

\section{REFUGIADOS AMBIENTAIS}

No contexto do debate sobre as mudanças climáticas, o tema dos deslocamentos humanos forçados em virtude de desastres ambientais surge como situação jurídica nova, não contemplada pelo Direito Internacional, uma vez que os chamados "refugiados ambientais" não se enquadram nas categorias tradicionais existentes, bem como não estão compreendidos nos demais grupos de migrantes reconhecidos em tratados e convenções internacionais vigentes.

Diante disso, necessário se faz analisar como essa temática vem sendo tratada dentro da literatura jurídica internacional, buscando identificar as bases para a construção de um sistema de proteção específico para essa nova categoria de refugiado, reconhecendo formalmente um status jurídico para as pessoas que se encontram nessa condição, sobretudo no ordenamento jurídico brasileiro.

\subsection{Contextualização e conceituação}

A migração motivada por fatores ambientais é um fenômeno recorrente na história da humanidade desde os seus primórdios. Pode-se dizer que estas migrações foram determinantes para o povoamento da Terra, uma vez que permitiram a descoberta, ocupação e exploração de novas áreas do globo.

Vislumbra-se que existe uma correlação estatisticamente significativa entre migrações e a degradação ambiental, incluindo mudanças climáticas, conforme entendimento de Afifi e Warner (2007).

Nesse sentido, segundo o Relatório Mundial de Desastres de 2001, publicado pela Cruz Vermelha Internacional, atualmente mais pessoas são forçadas a abandonar 
suas casas em virtude de desastres ambientais do que guerras. A Cruz Vermelha estima que aproximadamente 25 milhões de pessoas poderiam ser consideradas, atualmente, refugiados ambientais.

Fenômenos ambientais que influenciam as migrações humanas têm sido registrados com maior frequência nas últimas décadas, sobretudo em razão das alterações climáticas que, de alguma forma, tornam imprópria a vida humana em determinado espaço geográfico (WARNER et. al., 2009).

Com base nisso, segundo estimativa do Alto Comissariado das Nações Unidas para os Refugiados (ACNUR), apresentada em 2008, aproximadamente 250 milhões de pessoas serão levadas a se deslocar no curso deste século, em razão das mudanças climáticas, das condições meteorológicas extremas, da diminuição das reservas de água e da degradação das terras agrícolas, eventos esses resultantes do aquecimento global e da ação antrópica.

Dessa maneira, a análise da vulnerabilidade socioambiental e dos desastres ambientais são maneiras pelas quais se podem buscar compreender como os efeitos humanos sobre a natureza e aqueles produzidos independentemente da ação humana têm o potencial de afetar a vida de milhões de pessoas por todo o mundo (BIRKMANN, 2006).

Após as considerações iniciais acerca da relação existente entre as mudanças climáticas e o aumento do número de deslocamentos humanos forçados em decorrência dessas mudanças, faz-se necessário analisar o conceito de refugiado.

Inicialmente, tem-se que à luz do Direito Internacional dos Refugiados, no regime internacional de proteção consagrado na Convenção de Genebra relativa ao Estatuto dos Refugiados de 1951, emendada pelo Protocolo de 1967, considera-se refugiado:

Art. 1․ Toda a pessoa que, em razão de fundados temores de perseguição devido à sua raça, religião, nacionalidade, associação a determinado grupo social ou opinião política, encontra-se fora de seu país de origem e que, por causa dos ditos temores, não pode ou não quer fazer uso da proteção desse país ou, não tendo uma nacionalidade e estando fora do país em que residia como resultado daqueles eventos, não pode ou, em razão daqueles temores, não quer regressar ao mesmo. 
Contudo, alguns autores, a exemplo do renomado jurista francês Michel Prieur (2014), defendem que o dispositivo legal supramencionado não inclui os chamados "refugiados ambientais", expressão que foi cunhada na década de 1970 por Lester Brown (BLACK, 2001).

Tal entendimento se deve ao fato de que, nos termos da referida Convenção de Genebra sobre o Estatuto dos Refugiados de 1951, "refugiado é a pessoa que teme ser perseguida em razão da sua raça, da sua religião, da sua nacionalidade, do fato de pertencer a um determinado grupo social ou em função de suas opiniões políticas".

Diante disso, segundo Prieur (2014), as situações previstas na referida Convenção de Genebra "não abrangem os refugiados climáticos e ambientais. Daí se falar, também, em "deslocados" climáticos e ambientais" (PRIEUR, 2014, p. 998-1000).

No mesmo sentido é o entendimento de Essam El-Hinnawi (1985), divulgado em relatório apresentado ao Programa das Nações Unidas para o Meio Ambiente (PNUMA), o qual afirma que:

Os refugiados ou deslocados ambientais, em termos gerais, são as pessoas forçadas a deixar o lugar em que vivem, de maneira temporária ou permanente, em virtude de eventos climáticos e ambientais, de origem natural ou humana, que colocam em perigo a sua existência ou afetam seriamente a sua condição de vida. (SILVA, 2009, p. 46);

Diante do exposto, vislumbra-se que os refugiados ou deslocados climáticos são as pessoas que deixaram ou estão na iminência de deixar em um futuro próximo o lugar em que vivem em razão de uma súbita ou gradual alteração do meio natural causada pelos impactos das mudanças climáticas (MIRRA, 2017).

Por fim, merece destaque o conceito apresentado pela Organização Internacional para a Migração (OIM), que estabelece que:

Migrantes ambientais são pessoas ou grupos de pessoas que, por razões prementes de mudanças repentinas ou progressivas no meio ambiente que afetam adversamente suas vidas ou condições de vidas, são obrigados a deixar suas moradias habituais, ou escolhem fazê-lo, seja temporariamente ou permanentemente, e que se movem seja dentro de seu país ou para o exterior (INTERNATIONAL ORGANIZATION FOR MIGRATION, 2007). 
Todavia, vislumbra-se que ainda não é possível determinar, tanto na doutrina quanto na jurisprudência, uma definição clara e universalmente aceita da expressão "migrantes ambientais", embora diversos autores ofereçam definições próprias, por vezes criando subcategorias mais específicas de migrantes para cada situação de adversidade ambiental (MCCUE, 1993; KING, 2006).

Por fim, para Jane McAdam (2009), a imprecisão do conceito de migrantes ambientais não impede a tomada de medidas relativas a esse grupo; ao contrário, possibilita que essas medidas sejam mais flexíveis.

Nesse sentido, em que pese todos os conceitos apresentados, bem como todas as críticas doutrinárias sobre as tentativas de se chegar a um consenso, o mais importante é que se tenha em mente o fato de que em ambos os casos, o fator primordial para a migração ou deslocamento se deve às mudanças climáticas que vêm se intensificando, e por este motivo, independentemente do nome ou conceito, devem ser garantidos a essas pessoas seus direitos fundamentais.

\section{PROTEÇÃO JURÍDICA DOS REFUGIADOS AMBIENTAIS NO BRASIL}

No Brasil, o Comitê Nacional para os Refugiados (CONARE), órgão de deliberação coletiva, ligado ao Ministério da Justiça e com composição multidisciplinar (inclusive por entidades religiosas) que trata dos refugiados lato sensu.

O CONARE tem como função principal "analisar os pedidos e declarar o reconhecimento, em primeira instância, da condição de refugiado, bem como por orientar e coordenar as ações necessárias à eficácia da proteção, assistência e apoio jurídico aos refugiados".

Além disso, ressalta-se que "o elevado grau de institucionalização da matéria atingido no Brasil com a criação do CONARE evidencia os avanços promovidos nessa matéria pelo Governo, em parceria com a sociedade civil brasileira" (ITAMARATY, 2016).

Cumpre registrar que o Brasil adotou um conceito mais amplo de refugiado, fundamentado na Convenção de Genebra de 1951 e, principalmente, na Declaração de Cartagena de 1984. 
Vislumbra-se que o instituto jurídico do refúgio no Brasil é regulado pela Lei 9.474/1997 que define os mecanismos para implementação do Estatuto dos Refugiados de 1951 no Brasil, sobretudo, em relação ao "devido processo legal do refugiado". A referida lei dispõe que:

Art. 1 Será reconhecido como refugiado todo indivíduo que:

I - devido a fundados temores de perseguição por motivos de raça, religião, nacionalidade, grupo social ou opiniões políticas encontre-se fora de seu país de nacionalidade e não possa ou não queira acolher-se à proteção de tal país; II - não tendo nacionalidade e estando fora do país onde antes teve sua residência habitual, não possa ou não queira regressar a ele, em função das circunstâncias descritas no inciso anterior;

III - devido a grave e generalizada violação de direitos humanos, é obrigado a deixar seu país de nacionalidade para buscar refúgio em outro país. (grifei)

Com base nisso, a Lei 9.474/97 concede aos refugiados direitos e deveres específicos, diferenciando dos direitos relativos aos demais estrangeiros e trata da questão da entrada, do pedido de refúgio, das proibições ao rechaço, à deportação e à expulsão e ainda regula a questão da extradição dos refugiados.

Atenta à dimensão dinâmica dos direitos humanos, a legislação brasileira deu uma importante contribuição à redefinição do conceito de refugiado, acrescentando ao lado da figura do "perseguido político" também a figura da vítima de violação de direitos humanos em geral.

De acordo com a legislação brasileira, portanto, paralelo ao refugiado de guerra ou aquele perseguido por motivos políticos, étnicos ou religiosos, encontra-se o refugiado de grave e generalizada violação de direitos humanos. Vislumbra-se que essa redefinição confere uma condição mais abrangente e adequada à proteção de direitos humanos no Brasil.

Sendo assim, segundo Ramos (2011), na situação anterior, as "vítimas de violação de direitos civis e políticos poderiam, sob certas circunstâncias, ser abrigadas sob o estatuto do refugiado, mas as vítimas de violação de direitos básicos, como direito à saúde, moradia, educação e até alimentação, não". Todavia, com o novo parâmetro jurídico, de acordo com a Lei 9.474/97, a situação se modificou. 
Ademais, a respeito da questão ambiental, a própria Constituição Federal de 1988 prevê no caput do artigo 225 que "todos têm direito ao meio ambiente ecologicamente equilibrado, bem de uso comum do povo e essencial à sadia qualidade de vida, impondo-se ao Poder Público e à coletividade o dever de defendê-lo e preservá-lo para as presentes e futuras gerações" (BRASIL, 1988).

Com base nisso, ante à grave violação dos direitos humanos fundamentais sofrida pelos deslocados decorrentes de desastres naturais, bem como a garantia constitucional do direito de todos ao meio ambiente ecologicamente equilibrado, mister se faz que o ordenamento jurídico pátrio reconheça o status de refugiado a esses indivíduos, garantindo assim a sua proteção legal.

\section{CONSIDERAÇÕES FINAIS}

O presente artigo teve como objetivo geral a análise da existência de mecanismos de proteção jurídica para os refugiados ambientais dentro do ordenamento jurídico brasileiro.

Com relação aos objetivos específicos, buscou-se analisar como sé dá o processo de acolhimento, assistência e efetivação dos direitos dos refugiados no âmbito nacional, tanto na esfera pública quanto por intermédio de instituições do terceiro setor.

Em suma, foi analisado como essa temática dos refugiados ambientais vem sendo tratada dentro da literatura jurídica internacional e pátria, buscando identificar também as bases para a construção de um sistema de proteção específico para essa nova categoria de refugiado, reconhecendo formalmente um status jurídico para as pessoas que se encontram nessa condição, sobretudo no ordenamento jurídico brasileiro.

Nesse sentido, esta monografia fundamentou-se em um conjunto de autores e dispositivos legais que apresentam reflexões acerca do problema objeto da pesquisa, principalmente com relação ao conceito de refugiado ambiental e suas controvérsias.

Ademais, ressalta-se que esta temática, dotada de relevância jurídica e socioambiental, em que pese sua grande importância e atualidade, encontra-se ainda 
em um estágio embrionário de produção acadêmica e científica, vez que há uma escassez de fontes e materiais relacionados ao tema, o que justifica a necessidade de realização desta pesquisa.

Dessa forma, vislumbra-se que o presente trabalho fornecerá elementos que poderão contribuir para o entendimento da problemática que envolve a questão dos refugiados ambientais, principalmente no âmbito da realidade brasileira, servindo como fonte para futuras pesquisas e trabalhos acadêmicos nesta importante área do Direito Internacional Ambiental, a qual está diretamente relacionada também com o Direito Internacional dos Direitos Humanos.

Em que pese todos os conceitos apresentados, bem como todas as críticas doutrinárias sobre as tentativas de se chegar a um consenso, o mais importante é que se tenha em mente $o$ fato de que em ambos os casos, o fator primordial para a migração ou deslocamento se deve às mudanças climáticas que vêm se intensificando, e por este motivo independentemente do nome ou conceito devem ser garantidos a essas pessoas os direitos fundamentais.

Sendo assim, com o objetivo de incluir os refugiados ambientais no sistema de proteção internacional, vislumbra-se que uma das alternativas seria a modificação dos instrumentos convencionais internacionais já existentes, como a aludida Convenção relativa ao Estatuto dos Refugiados (Convenção de Genebra de 1951), para incluir, em seus textos respectivos e em protocolos adicionais, a proteção dos refugiados ambientais.

Nesse sentido, cumpre registrar que a legislação brasileira está na vanguarda da proteção jurídica dos refugiados ambientais, uma vez que ampliou o conceito de refugiado com a inclusão das vítimas de grave e generalizada violação de direitos humanos em seu país de origem, o que tem possibilitado uma interpretação analógica por parte da jurisprudência, conferindo uma condição aberta e adequada à proteção ampla de direitos humanos no Brasil, inclusive reconhecendo os indivíduos deslocados em decorrência de desastres naturais como refugiados propriamente ditos.

Com isso, se faz necessário manter o sistema de proteção internacional e nacional dos refugiados em constante aprimoramento para que se tenha uma maior 
eficácia diante dos novos desafios enfrentados pela comunidade internacional, sobretudo de caráter ambiental e humanitário.

Por fim, ressalta-se que o tema em questão apresenta reflexões que podem possibilitar uma maior conscientização tanto a respeito da questão da necessidade de preservação do meio ambiente a fim de diminuir os efeitos das mudanças climáticas, bem como no que tange ao respeito às diferenças étnicas e culturais dos indivíduos em situação de refúgio recém-chegados no país, o que poderia facilitar o processo de adaptação e inclusão social dos mesmos.

\section{REFERÊNCIAS}

AFIFI, Tamer; JÄGER, Jill (Eds.). Environment, Forced Migration and Social Vulnerability. Heidelberg: Springer, 2010.

BANKOFF, Greg; FRERKS, Georg; HILHORST, Dorothea. Mapping Vulnerability: disasters, development, and people. London: Earthscan, 2004.

BIRKMANN, Jörn. Measuring Vulnerability to Natural Hazards: towards disaster resilient societies. Tokyo: United Nations University Press, 2006.

BLACK, Richard. Environmental Refugees: myth or reality? Working Paper n. 34, Geneva, March, 2001.

BRASIL. Lei no 9.474 de 22 de julho de 1997. Define mecanismos para a implementação do Estatuto dos Refugiados de 1951, e determina outras providências. In: Diário Oficial da União, Brasília, DF, 23 jul. 1997. Disponível em: http://www.planalto.gov.br/ccivil_03/leis//9474.htm. Acesso em: 20 mar. 2019.

EL-HINNAWI, Essam. Environmental Refugees. Nairobi: UNEP, 1985.

HARDIN, Garrett. The Tragedy of the Commons. Science, vol. 162, 13 December 1968, p.1243-1248.

JUBILUT, Liliana Lyra. O Direito Internacional dos Refugiados e sua Aplicação no Ordenamento Jurídico Brasileiro. São Paulo: Método, 2007.

MIRRA, Álvaro Luiz Valery. Participação, Processo Civil e Defesa do Meio Ambiente. São Paulo: Letras Jurídicas, 2011, p. 104-105. 
PRIEUR, Michel. Droit de L'environnement, Droit Durable. Bruxelles: Bruylant, 2014, p. $998-1000$.

SILVA, Solange Teles da. O Direito Internacional do Meio Ambiente. Belo Horizonte: Del Rey, 2009, p. 46).

TRINDADE, Antônio Augusto Cançado. A Humanização do Direito Internacional. Belo Horizonte: Del Rey, 2006.

TRINDADE, Antônio Augusto Cançado. Direitos Humanos e Meio Ambiente: Paralelo dos Sistemas de Proteção Internacional. Porto Alegre: Sergio Antonio Fabris, 1993, p. 115 e 122 .

UNITED NATIONS. Convention and Protocol Relating to the Status of Refugees. New York, October 4, 1967. Disponível em: https://www.unhcr.org/protection/basic/3b66c2aa10/convention-protocol-relating-statusrefugees.html. Acesso em: 22 mar. 2019. 